\title{
Operating conditions of hydraulic structures and results of their multi-factor analysis
}

\author{
Alexey Romanov ${ }^{1}$, Sergey Evdokimov ${ }^{1, *}$, and Alla Orlova ${ }^{1}$ \\ ${ }^{1}$ Samara State Technical University, Academy of Architecture and Civil Engineering, \\ Molodogvardeyskaya St., 194, Samara, 443001, Russia
}

\begin{abstract}
Nowadays, the state of Zhiguli Hydroelectric Station (HS) and its main hydraulic structures is controlled by observation of control and measuring equipment installed on these structures. There are systematic inspections and surveys carried out by both the hydroelectric power station personnel and by invited experts. The last analysis of the state of HS and its hydraulic structures was made in 1991. Since that time, a computerbased information and diagnostic system for monitoring the state of hydraulic structures has been introduced at HS. This system introduction caused the need to pay more serious attention to the reliability of the results obtained by means of control and measuring equipment, because the system monitored the condition of all hydraulic structures according to these results. Thus, the purpose of the research is to perform a multi-factor analysis of HS state and its hydraulic structures according to field studies results of all the devices installed in water-retaining structures. The results show impervious elements of HS underground circuit are not effective enough for specific geological conditions in terms of clearing the filtration head. The main drop of water head in the base occurs on HS building upper cutoff, i.e. in this zone there is a maximum filtration gradient, which is very dangerous. This process should be carefully monitored. It was revealed that several piezometers in the base do not work or their indications are not reliable, therefore it is necessary to repair and, in some cases, replace them. In future, it is necessary to equip main piezometers of HS with remote water level measuring sets and to make an automated system of condition monitoring.
\end{abstract}

\section{Introduction}

Nowadays, the state of Zhiguli Hydroelectric Station (HS) and its main hydraulic structures is controlled according to the data of control and measuring equipment observations installed on these structures. There are also systematic inspections and surveys carried out by both the hydroelectric power station personnel and invited experts. As a result of the

\footnotetext{
*Corresponding author: sali5@mail.ru
} 
analysis of field studies and surveys, qualified experts make a conclusion on the hydraulic structure state.

In accordance with the latest version of the Maintenance Rules for Power Plants (RD 34.20.501-95), the wording "the analysis of field studies results" was replaced by the wording "multifactorial analysis of the structure state". This makes it possible to evaluate all the operating factors when analyzing the state of hydraulic structures of waterworks.

An obvious factor in all the cases is that the analysis of the structures state should be carried out every five years by qualified experts. In this analysis, assessment of reliability and validity should be made in addition to structures state assessment, obtained from control and measuring equipment, as well as sufficient operability of the equipment itself.

The last analysis of hydraulic structures state of Zhiguli Hydroelectric Station was carried out in 1991. Since that time computer information and diagnostic system for monitoring the structures state began to be introduced at the hydroelectric station. The introduction of this system caused the need to pay the most serious attention to the reliability of the results obtained with the help of control and measuring equipment, as the structure state control is being carried out on their basis.

The article gives an analysis of field studies from 1975 to 2015 of all the equipment installed in water-retaining structures in Zhiguli Hydroelectric Station [1-3].

For some groups of equipment, the whole period data were used for analysis.

The authors carried out a multifaceted analysis of the hydraulic structures state of Zhiguli Hydroelectric Station on the basis of the obtained materials processing. This analysis is given below.

\section{Materials and methods}

HS building is situated on the right bank of the Volga river and its base is embedded in the ancient ravine bedrock formed as a result of Zhiguli massif erosion.

Base plates with cutoff and sheet piling, as well as anchor upstream apron are the impervious elements of Zhiguli HS. The sheet piling is interfaced with sheet piles of rightand left-bank retaining walls, thus preventing offline filtration. To remove the filtration water and pressure, subsurface drain is installed behind the upper cutoff of HS building, linked with lower pool.

The base under the HS building is not homogeneous: sections $1-6$ are located on the gully, where the HS building crashes into dense Kinel clay with its upper cutoff. In the river bed part, where the crest of Kinel clays is located deeper, the upper cutoff rests on the relatively more permeable quaternary mindel-riska soil sediments [4-6].

To control the filtration mode, 186 piezometers were installed at the base of the station building and in conjunction with the retaining walls. One group of piezometers controls the work of entrance section of HS building: anchor upstream apron, SCS cutoff and upper cutoff of HS building base plate. The second group of devices controls filtration pressure on HS building base plate.

366 sedimentary marks (currently there are 361), 84 slit-metering devices (currently there are 76) and 23 range marks (currently there 30) were installed to control the deformation of HS building and associated devices.

The impervious circuit of HS building is known to have been created by the base plate of trash-rack structure with cutoff, sheet piling, anchor upstream apron and upper cutoff of HS building [7,8].

Observations on piezometers controlling the filtration mode at the entrance area under HS building showed that the efficiency of this section in terms of pressure reducing was small. So, behind the upper sheet pile for sections $1,5,6,7$, water head drop was in the range of 20 to $30 \%$. Within the sections $3-4$, water levels measured by piezometers behind 
the sheet pile were equal to the water levels in the reservoir, i.e. there was no head clearing. The greatest head clearing on the upper sheet pile was observed in sections 8, 9 and 10 and was $30-40 \%$ of the head. The main head decrease in the base occurred on the upper HS building cutoff. This is quite natural, because there was surface drain behind upper cutoff that it had entrance to lower pool.

Thus, impervious elements circuit on the entrance part of the HS building are not effective enough for specific geological conditions in terms of clearing the filtration head.

Studies have shown that the greatest head drop on the damp section of HS building is observed in sections 7, 8 and 9. Consequently, at these sections base a minimum pressure gradient is observed under upper cutoff of the building.

The maximum pressure gradient is observed at the base of sections 3 and 4 , and it is somewhat smaller at the base of sections 5 and 10 . For sections 3,4 it is $0.82-0.85$, for sections 5, $10-0.6$ and 0.9 respectively.

Maximum gradients for loam are 0.8 , and for clays 1.35 . Since the zone of sections 1-4 of HS building is embedded in dense Kinel clays with its upper cutoff, the measured head gradient does not exceed the permissible values. However, it should be borne in mind that there are no piezometers directly below the cutoff, so it is possible only to assume gradient on the length between piezometers P3 and P4 or P3 and surface drain. In fact, water level measured by piezometer P3 can be observed much closer to surface drain, for example, directly under cutoff. As a result, the actual pressure gradient will be much greater than the one mentioned above.

All this makes it necessary to provide constant, especially careful monitoring over the piezometers at the base of sections 3, 4, 5 and 10 .

Thus, all the data observed confirm that zone under the upper cutoff of sections $3,4,5$ and 10 of HS building is the most dangerous from the viewpoint of ensuring the filtration stability of the base. The main controlling parameter for this zone should be the gradient of filtration head, measured between piezometers P3 and P4.

It is also interesting to analyze the change in piezometric levels measured by equipment during operation periods. The readings of piezometers P1, P2 and P3 fluctuate in accordance with upper pool. The levels in piezometer P4, as well as piezometers P7, P8, P9 and P10 change synchronously with the fluctuations in the lower pool levels.

In general, the indications of control piezometers (P1, P2, P3, P4) for the entire operation period have horizontal approximation, i.e. except for fluctuations associated with changes in the levels of UP and LP, they do not change over time. Readings of piezometers P2 and P3 in sections 1 and 2 are considered to be exceptions. Over the past 35 years, P2 piezometer readings under these sections have been decreasing with intensity of $0.1 \mathrm{~m} /$ year; piezometer $\mathrm{P} 3$ readings with intensity of $0.2 \mathrm{~m} /$ year.

If these data are reliable, similar decrease indicates the colmatation of filtration pathways in the upstream apron part of these sections base, that in turn provides filtration gradients reduction in the upper cutoff zone.

The reverse process - piezometric levels growth is observed by P3 piezometer at the sections base 7 and 9, growth rate is $0.1 \mathrm{~m} /$ year, and that indicates an increase in the head gradient under the upper HS building cutoff. This process for the sections mentioned is not dangerous, as the filtration head gradients are in the range of $0.2-0.28$, that is much lower than the accepted values [9].

Observation piezometers data analysis showed that they are quite efficient and provide reliable information. However, there is a number of piezometers that require verification and repairing: P4 in sections 3, 5 (large scatter of readings) and 2, 6, P5 in section 6 and P7 in sections 1 and 7 . 


\section{Results}

To monitor subsidence and relative displacements of sections, powersites of slit-metering devices were installed on HS building; that is No. 3 from the upstream pool side (in the zone of upper pool shutter) and No. 5 from the upstream pool side (in the zone of emergency-repair shutters of the lower pool). Moreover, two powersites of slit-metering devices were installed on trash-rack structure: No. 1 from the upper pool side and No. 2 from the upstream pool side.

Figure 1 shows the graphs of the average sediments of HS building, identified by four slit-metering devices of each section, and their approximating lines. The average sediments of sections 1-6 are close to each other and have the same pattern of changing over time. The highest sediment values of these sections were in the range of 45-60 $\mathrm{mm}$ at the end of 2001. Since their growth intensity in time did not exceed $0.3 \mathrm{~mm}$ per year, they can be considered as damped.

Large subsidence were observed in sections 8-10. In 2001 their value was 105-125 mm. Their growth intensity in time is 2-3 times greater, nevertheless, does not exceed $1 \mathrm{~mm}$ per year. Therefore, in general, the subsidence of HS building should be assessed as damped.

Sections 1-6 subsidence at the end of 2001 does not exceed $45 \mathrm{~mm}$, sections 8-10 subsidence are within the range of $90-160 \mathrm{~mm}$. Uneven subsidence along the building length confirms the soils heterogeneity at HS building base. At the base of sections 1-6, soils have high density and, consequently, a greater deformation modulus than the soils located at the base of sections 8-10.

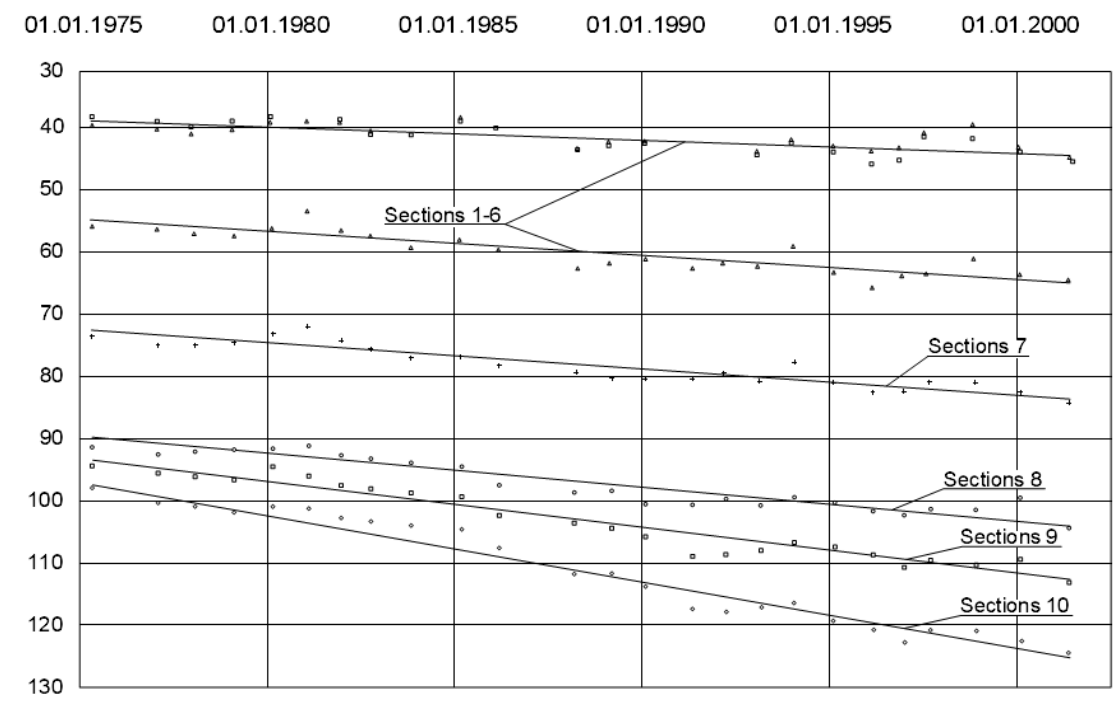

Fig. 1. Average subsidence approximation of HS building sections, measured by slit-metering marks.

As the curve subsidence analysis of HS building and also trash rack structures along the longitudinal gates showed that the subsidence of the lower and upper pools was almost identical. At the same time, the HS building subsidence from the upper and lower pool sides within 1-5 sections are close to each other, and within 6-10 sections they differ by 2 or more times, i.e. these sections have a certain inclination towards the upper pool. The greatest slope from 1975 to 2015 was formed in sections 8,9 and in section 10 partially, where the subsidence marks differences in gates 3 and 5 are about $100 \mathrm{~mm}$. In sections 1-5 this difference does not exceed $20-30 \mathrm{~mm}$. Thus, the uneven formed subsidence is small and far from the limiting values 10]. 
Despite the fact that the building subsidence is practically damped, observations on slitmetering marks must be continued, the observations accuracy being even higher than the one at the beginning of operational period. Modern geodetic instruments should be used and thorough monitoring of surveying reference points should be carried out.

In no case the frequency of observations should decrease, observations should be conducted at least once in every 2 years, or even annually.

Horizontal displacements measuring, carried out on slit-metering marks gives only a relative subsidence value of the sections, and that does not allow to estimate the overall horizontal movements of the building. Nevertheless, according to available observations, it can be stated that the measured horizontal displacements of sections along the flow are within the observations accuracy. The largest movements are measured in the direction of joints opening and closing.

Figure 2 shows the graphs approximation of opening-closing cross-sectional joints along the Gate 3. As can be seen, the joints are constantly closed, their closing intensity during last years being the same and damping of this process is not visible. The only exception is the joint in section 9 (gate 3), where a continuous joint opening is observed.

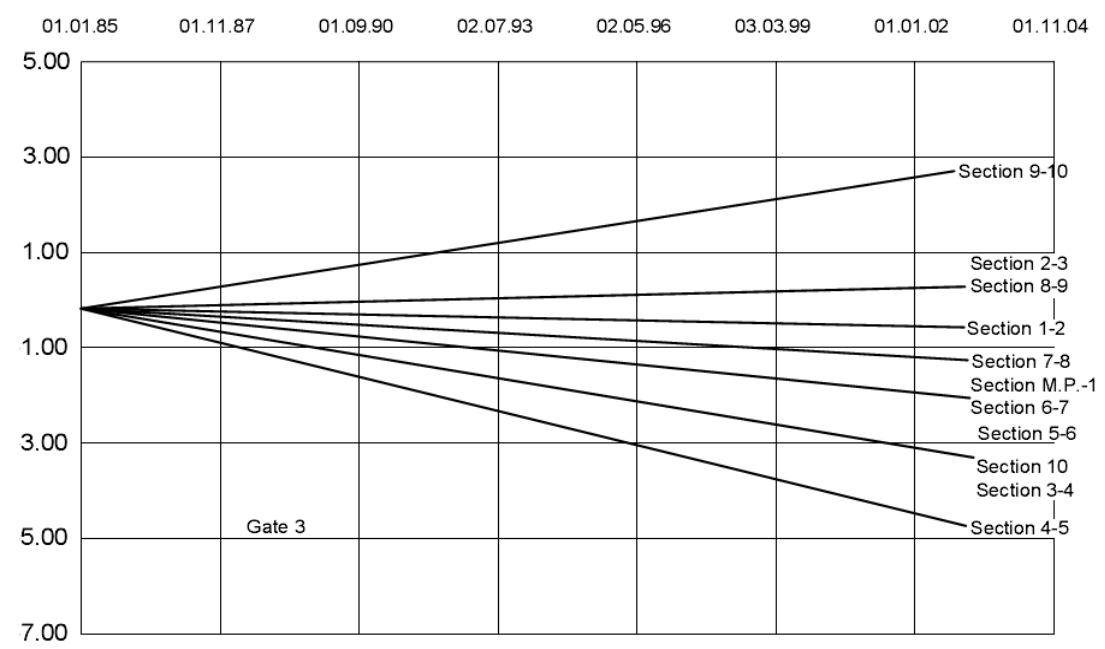

Fig. 2. Approximating lines comparison of joints opening and closing between HS building sections.

The same pattern of joint closure (except for joints in sections 3 and 8 ) is observed with reference to slit-metering devices installed in the pattern over $40-50 \mathrm{~m}$ below gates 5 and 3 .

Apparently, these long deformations have the creep character and in general are not dangerous to the structures.

\section{Discussions}

Observations analysis of filtration regime at the base showed that, the impervious HS building circuit, including base plate with cutoff and sheet piling, as well as anchor upstream apron work insufficiently effectively in these geological conditions. Thus, under sections $1,5,6,7$ the sheet pile clears $20-30 \%$ of the head and in the area of sections 3-4 does not clear the head at all.

As a result, the filtration gradients lie within the range of 0.6 to 0.9 directly under the upper cutoff of sections 3, 4 and to less extent of sections 5 and 10, which is close to the 
limiting values. Taking into account that it is not possible to measure the piezometric head distribution directly under the cutoff, the actual gradient can be much larger.

Several piezometers at the base do not work or their indications are not relible. These piezometers must be repaired or replaced.

Subsidence observations of the station showed that minimum subsidence values are observed on sections 1-6, and maximum - on sections 8-10. This fact allows to assume that the soil at the base 8-10 has a lower density and is more deformative. In general, the subsidence values even in sections 8-10 are very small, and their growth in time does not exceed $1 \mathrm{~mm}$ per year, which indicates their damping.

Horizontal deformations of the section in the direction along the flow are practically absent, and the transverse deformations measured with the slit-metering device indicate continuous joints closing with undamaged rate. This process has linear nature and almost all the section joints is in doubt in the instruments readings reliability. It can be recommended to perform special test measurements to check the reliability of observation results.

\section{Conclusions}

The main conclusions on the work can be formulated as follows:

1. The impervious elements of the underground circuit of HS building, especially at the exit section, turned out to be insufficiently effective for specific geological conditions of the base from the point of view of filtration head clearing. Thus, the main head drop of water at the base of the sections under consideration occurs on the upper HS building cutoff, i.e. the maximum filtration gradient is observed in this zone. This seems to be very dangerous; therefore, this process should be carefully monitored, especially in the area of sections 3 and 4 .

2. $\mathrm{P} 3$ and $\mathrm{P} 4$ are the main piezometers that determine the reliability of impervious elements devices of the entire HS building. However, special attention should be paid to piezometers in sections 3, 4, and 10. In the future, it is necessary to equip the main piezometers of the HS building with remote water level measuring sets and to make an automated system of condition monitoring.

\section{References}

1. A.A. Romanov, S.V. Evdokimov, Scientific review, 7 (2015

2. A.A. Romanov, S.V. Evdokimov, Industrial and civil construction, 6 (2015)

3. M.I. Balzannikov, V.A. Zubkov, N.V. Kondratieva, V.A. Khurtin, Hydraulic engineering, 6 (2013)

4. A.S. Lychev, T.V. Dormidontova, Proceedings of high schools. Building, 6 (2002)A. Mecke, I. Lee, J.R. Baker jr., M.M. Banaszak Holl, B.G. Orr, Eur. Phys. J. E 14, 7 (2004)

5. M.I. Balzannikov, M.V. Rodionov, Yu.E. Senitsky, Privolzhsky scientific journal, 2 (2012)

6. M.I. Balzannikov, B.G. Ivanov, A.A. Mihasek, System for state managing of hydraulic structures, 7 (2012)

7. T.B. Dormidontova, V.P. Popov, Scientific review, 4 (2012)

8. M.I. Balzannikov, I.S. Kholopov, V.Yu. Alpatov, Application of latticed spatial metal structures in the coatings of turbine room of hydroelectric power stations, 28 (2012) 
9. M.I. Balzannikov, V.A. Seliverstov, Investigations of the influence of flow dividers for use in water intake devices of hydroelectric power plants, 3 (25) (2009)

10. T.B. Dormidontova, V.V. Kiryakov, Naukovedenie, 2, 7 (2015) 